\title{
Inhalation of Salvianolic acid B Prevents Fine Particulate Matter-Induced Acute Airway Inflammation and Oxidative Stress by Downregulating the LTR4/MyD88/NLRP3 Pathway
}

\section{Liucheng Li}

Zhejiang University School of Medicine Sir Run Run Shaw Hospital

\section{Liandi Kan}

Zhejiang University School of Medicine Sir Run Run Shaw Hospital

Qiangmin Xie ( $\square$ xieqm@zju.edu.cn )

Zhejiang University School of Medicine https://orcid.org/0000-0002-7975-9962

\section{Research}

Keywords: salvianolic acid B, fine particulate matter, airway inflammation, oxidative stress, MyD88

Posted Date: September 7th, 2021

DOI: https://doi.org/10.21203/rs.3.rs-844937/v1

License: (c) (i) This work is licensed under a Creative Commons Attribution 4.0 International License.

Read Full License 


\section{Abstract}

Background: Air pollution is a serious threat to human health. Inhaled fine particulate matter (PM2.5) can cause inflammation and oxidation in the airway; however, the mechanisms responsible for this effect have yet to be elucidated and there are no specific drugs that can prevent and treat this condition. In the present study, we investigated the effects and mechanisms underlying the inhalation of salvianolic acid $B$ (SalB) on PM2.5-induced airway inflammation and oxidation.

Methods: We used a PM2.5-induced mouse model of airway inflammation and oxidation, along with a human epithelial cell model, to study the action and mechanisms of SalB by histopathology, real-time quantitative polymerase chain reaction, enzyme-linked immunosorbent assays, flow cytometry, and western blotting.

Results: SalB treatment markedly inhibited the PM2.5-induced increase in the number of neutrophils and macrophages in bronchoalveolar lavage fluid, improved the infiltration of inflammatory cells in lung tissue, and reduced injury in the alveolar septum. Furthermore, SalB reduced the mRNA and protein levels of interleukin (IL)-1 $\beta$, tumor necrosis factor (TNF)-a, keratinocyte (KC), and transforming growth factor (TGF)- $\beta 1$ in lung tissues, and the protein levels of IL-1 $\beta$, TNF- $\alpha$, IL-8, IL- 6 and TGF- $\beta 1$ in human epithelial cells. SalB treatment also significantly reversed the reduction of levels of superoxide dismutase, catalase, glutathione and glutathione peroxidase in lung tissue and reduced the levels of reactive oxygen species in human epithelial cells induced by PM2.5. Furthermore, SalB and the myeloid differentiation primary response 88 (MyD88) inhibitor ST2825, inhibited the expression levels of toll-like receptor 4 (TLR4), MyD88, tumor necrosis factor receptor associated factor 6 (TRAF-6), and NOD-like receptor protein 3 (NLRP3), as well as the phosphorylation of downstream signals extracellular signal regulated kinase $1 / 2$ (Erk1/2) and P38 MAP kinase (P38) in lung tissue and epithelial cells.

Conclusion: SalB protects against PM2.5-induced airway inflammation and oxidation in a manner that is associated with the inhibition of the TLR4/MyD88/TRAF-6/NLRP3 pathway and downstream signals ERK1/2 and P38.

\section{Background}

Fine particulate matter (PM2.5) refers to suspended solids that are less than or equal to $2.5 \mu \mathrm{m}$ in size and can contain a range of complex elements, including organic carbons, ions, heavy metals, bacteria, and viruses. PM2.5 can readily gain access to the alveolar terminals, pass through the alveoli into the blood, and then be transported to other organs and tissues [1, 2]. The inhalation of PM2.5 into the respiratory tract leads to the stimulation of epithelial cells in the airways; this releases inflammatory factors that induce the accumulation of inflammatory cells in the lung tissue and an oxidative stress response, ultimately leading to acute lung inflammation and oxidative stress [3]. Previous studies have confirmed that the airway inflammation and oxidative stress induced by PM2.5 is related to the NOD-like receptor protein 3 (NLRP3) inflammasome. ${ }^{4}$ When activated, the NLRP3 inflammasome stimulates 
activation of caspase- 1 and the subsequent conversion of pro-interleukin-1 $\beta$ into its mature bioactive form (IL-1 $\beta$ ). IL-1 $\beta$ is a multifunctional pro-inflammatory factor that plays a key role in the process of PM2.5-induced airway inflammation [4, 5]. In addition, there are other pathways by which PM2.5 can promote inflammation. For example, PM2.5 was shown to promote the transformation of macrophages into foam cells in the RAW264.7 cell line by upregulating the expression of the TLR4/MyD88/NFKB pathway [6]. Furthermore, both long- and short-term exposure to PM2.5 has been shown to increase the development of atherosclerosis in ApoE ${ }^{-/-}$mice. ${ }^{6}$ However, no specific preventative measure or therapeutic has been developed for PM2.5. Consequently, there is an urgent need to develop potential targets and drugs for the prevention and treatment of PM2.5.

Salvianolic acid B (SalB) is one of the main water-soluble compounds in Salvia miltiorrhiza and exhibits the highest content of total phenolic acid and the strongest activity. Salvia miltiorrhiza root (Dansen) is known for its anti-inflammatory, anti-oxidation, and anti-fibrosis effects, and has been used for a long period of time to treat a variety of diseases, including those affecting the cardiovascular system, the brain, lung, liver, kidney, and also a range of cancers [7-9]. In our previous research, we used the ovalbumin-induced mouse model of asthma to demonstrate that SalB attenuates hyperresponsiveness in the airway, infiltration by eosinophils, and the hyperplasia of goblet cells, and that these effects were regulated by MUC5AC protein in response to the inhibition of ERK1/2/P38 signaling [10]. However, it is not yet known whether SalB can alleviate PM2.5-induced airway inflammation. Existing pharmacokinetic studies have shown that the absolute bioavailability of SalB when administered orally is only $1.07 \%$ (Beagle dogs) [11] and 2.3\% (rats) [12]. Therefore, we considered the potential effect of SalB when inhaled as an aerosol. Delivery by inhalation provides an excellent opportunity for local treatment in the lungs. Ideally, this form of local administration results in a high concentration of the drug at the target organ and high levels of efficacy. However, the systemic concentration of the inhaled drug remains at low levels; therefore, adverse reactions are rare. In the present study, we evaluated the effect of SalB inhalation on the prevention and treatment of PM2.5-induced airway inflammation and oxidative stress in a mouse model. We also performed a range of in vitro experiments to investigate PM2.5-induced oxidative stress and inflammatory reaction in human bronchial epithelial cells and explore the potential signaling pathways involved.

\section{Materials And Methods}

Materials

Fine particulate matter (PM2.5) standard was purchased from Wuhan Zhuoyan Huabiao Technology Co., Ltd. (Wuhan, China). The PM2.5 standard was autoclaved to exclude bacteria and viruses. According to chemical analysis, the major elements contained in the PM2.5 standard were as follows: $1.5 \mu \mathrm{g} / \mathrm{mg}$ of $\mathrm{Pb}, 3.9 \mu \mathrm{g} / \mathrm{mg}$ of Al, $4.1 \mu \mathrm{g} / \mathrm{mg}$ of $\mathrm{Ca}, 5.1 \mu \mathrm{g} / \mathrm{mg}$ of $\mathrm{Na}, 5.5 \mu \mathrm{g} / \mathrm{mg}$ of $\mathrm{Zn}, 6.3 \mu \mathrm{g} / \mathrm{mg}$ of $\mathrm{Fe}, 11 \mu \mathrm{g} / \mathrm{mg}$ of $\mathrm{Si}$, and $14 \mu \mathrm{g} / \mathrm{mg}$ of $\mathrm{K}$. The standard also contained $79 \mu \mathrm{g} / \mathrm{mg}$ of organic carbon and $165 \mu \mathrm{g} / \mathrm{mg}$ of elemental carbon. 
Salvianolic acid B (SalB) was obtained from Shanghai Pureone Bio Technology Co. Ltd. (96\% purity, Shanghai, China) as a white powder and in a water-soluble form. SalB was prepared with saline as a range of solutions for inhalation $(2.5,7.5$, and $15.0 \mathrm{mg} / \mathrm{mL})$. The SalB solution was sprayed into the inhalation exposure tower with a jet nebulizer (BARI Co. Ltd., Germany). After the aerosol containing SalB had been filled, we removed $48 \mathrm{~mL}$ of aerosol from the exposure tower with a $50-\mathrm{mL}$ syringe (containing 2 $\mathrm{mL}$ of HPLC mobile phase). The syringe was sealed with a rubber stopper, allowed to stand for $1 \mathrm{~min}$, and the contents of the syringe were shaken violently and allowed to stand for $1 \mathrm{~min}$. Samples were taken in duplicate and a total of $96 \mathrm{~mL}$ of aerosol was collected for analysis. Once collected, the concentration of drugs in each of the $2 \mathrm{~mL}$ samples was detected by reversed phase high-performance liquid chromatography (Shimadzu, Japan) using a $\mathrm{C}_{18}$ column $(150 \times 4.6 \mathrm{~mm}, 5 \mu \mathrm{m})$ with acetonitrile and trifluoroacetic acid as the mobile phase and diluent, respectively. The flow rate was $2 \mathrm{~mL} / \mathrm{min}$ and the injection volume was $20 \mu \mathrm{L}$ under $225 \mathrm{~nm}$ ultraviolet spectrophotometry. Finally, the administered dose of SalB $(2.5,7.5$, and $15 \mathrm{mg} / \mathrm{mL})$ was converted by a formula to the actual inhaled doses of approximately $0.3,0.9$, and $1.8 \mathrm{mg} / \mathrm{kg}$, respectively; these data referred to mice in the exposure tower inhaling the medicine for a total of $8 \mathrm{~min}$.

Commercial kits were purchased from Jiancheng Bioengineering Institute (Nanjing, China) in order to determine the levels of superoxide dismutase (SOD), catalase (CAT), glutathione (GSH), and glutathione peroxidase (GSH-Px). 2', 7'-dichlorofluorescein diacetate (DCFH-DA) was purchased from AAT Bioquest (Sunnyvale, CA). PCR primers for mouse IL-1 $\beta$, TNF-a, KC, TGF- $\beta 1$, toll-like receptor 4 (TLR4), myeloid differentiation primary response 88 (MyD88), TNF receptor associated factor 6 (TRAF-6), and NLRP3, were all purchased from Shanghai Bioengineering (Shanghai, China). Enzyme-linked immunoassay (ELISA) kits for mouse IL-1 $\beta$, TNF- $\alpha$, KC, and TGF- $\beta 1$, and human IL- $1 \beta$, TNF- $\alpha$, IL- 8 , IL- 6 and TGF- $\beta 1$, were purchased from USCN Life Science, Inc. (Wuhan, China). Fetal bovine serum (FBS) was purchased from Hangzhou Sijiqing Biological Engineering Material Co., Ltd. (Hangzhou, China). RPMI 1640 medium, streptomycin, and penicillin were purchased from HyClone (Utah, USA). Primary antibodies for GAPDH, TLR4, MyD88, TRAF-6, NLRP3, extra-cellular signal-regulated kinase 1/2 (Erk1/2), and P38 mitogenactivated protein kinase (P38), were obtained from Cell Signaling Technology (Danvers, MA, USA). Secondary antibodies, electrophoresis apparatus, and electrophoresis chambers were obtained from BioRad (Hercules, CA, USA).

Animals

Male ICR mice ( $22 \pm 2 \mathrm{~g}$, 8 weeks old) were purchased from the Experimental Animal Center at the Zhejiang Academy of Medical Sciences (Hangzhou, China). The animals were housed at The Laboratory Animal Center of Zhejiang University in isolated ventilated cages (4-5 mice/cage) under a 12-h light/12-h dark cycle and received food and water ad libitum. The Institutional Animal Care and Use Committee of Zhejiang University approved the experimental protocols used in this study. To investigate the acute effect of PM2.5 in the development of airway inflammation and oxidative stress, the mice were randomly assigned to six groups: a control (saline) group, a model group (PM2.5), a SalB (2.5 mg/mL, equivalent to $0.3 \mathrm{mg} / \mathrm{kg})+$ PM2.5 group, a SalB $(7.5 \mathrm{mg} / \mathrm{mL}$, equivalent to $0.9 \mathrm{mg} / \mathrm{kg})+\mathrm{PM} 2.5$ group, a SalB (15 
$\mathrm{mg} / \mathrm{mL}$, equivalent to $1.8 \mathrm{mg} / \mathrm{kg})+$ PM2.5 group, and a ST2825 $(5 \mathrm{mg} / \mathrm{mL}$, equivalent to $0.6 \mathrm{mg} / \mathrm{kg})$ group. Mice in the PM2.5 groups were initially treated with $10 \mu \mathrm{g}$ of PM2.5 $(10 \mu \mathrm{L})$ via a tracheal spray needle and intratracheal instillation; subsequently, PM2.5 was administered intranasally on a daily basis for the next 5 days. Mice in the control group were treated with $10 \mu \mathrm{l}$ of normal saline. The SalB was sprayed into the exposure tower with a jet nebulizer (BARI Co. Ltd., Germany) for $8 \mathrm{~min} /$ day for $30 \mathrm{~min}$ prior to PM2.5 treatment.

Bronchoalveolar lavage

Six days after exposure to PM2.5, mice were anesthetized by the inhalation of isoflurane. Samples of bronchoalveolar lavage fluid (BALF) were then collected by cannulating the trachea and performing lavage with phosphate buffer solution (PBS) containing $1 \%$ bovine serum albumin (BSA) and $5000 \mathrm{IU} / \mathrm{L}$ heparin. BALF samples were centrifuged at $500 \times g$ for $10 \mathrm{~min}$ at $4^{\circ} \mathrm{C}$. The cells in each sample of BALF were then re-suspended in PBS, and the total number of leukocytes was counted. Cells were then stained with Wright-Giemsa stain; this allowed us to count the numbers of neutrophils, macrophages, and lymphocytes. The results are shown as the number of each type of cell in $1 \mathrm{~mL}$ of BALF.

Histopathological and immunohistochemical examination

Samples of tissue from the left lung of each experimental animal were fixed in $10 \%$ formalin for 15 days. The samples were then washed in ascending grades of ethanol, embedded in paraffin wax, and then sectioned into 3-4- $\mu \mathrm{m}$-thick sections. The sections of lung tissue were then stained with hematoxylineosin (H\&E) to evaluate the severity of inflammatory cell infiltration (neutrophils and macrophages) and edema in the alveolar septum. A scoring system was then used to assess severity (score) of inflammatory damage, as described previously ${ }^{10}$. Immunohistochemical (IHC) analysis of MyD88 was performed in accordance with the protocol provided with the Cell Signaling Technology Complex Kit (Danvers, MA, USA). Sections were incubated overnight at $4^{\circ} \mathrm{C}$ with a primary antibody against MyD88 (1:400). Positive binding sites were then visualized by staining with 3, 3'-diaminobenzidine; the intensity of staining was determined by Olympus software (Tokyo, Japan). Image Pro version 6.1 software (Houston, USA) was used for quantitative analysis of the staining. All analyses were performed in a blinded manner.

Cell culture

Human bronchial epithelial (16HBE) cells were acquired from the Cell Bank of the Chinese Academy of Sciences (Shanghai). The cells were continuously cultured in RPMI 1640 medium supplemented with $10 \%$ fetal bovine serum, $100 \mathrm{U} / \mathrm{mL}$ of penicillin, and $100 \mathrm{ng} / \mathrm{mL}$ of streptomycin at $37^{\circ} \mathrm{C}$ under a humidified atmosphere of $5 \% \mathrm{CO}_{2} / 95 \%$ air.

Determination of oxidative stress 
The 16HBE cells were treated with SalB and ST2825 and then exposed to PM2.5 $(200 \mu \mathrm{g} / \mathrm{mL})$ for $24 \mathrm{~h}$. Next, cells were collected by centrifugation and resuspended in 2',7'-Dichlorodihydrofluorescein diacetate (DCFH-DA) solution ( $5 \mu \mathrm{M} / \mathrm{L}$ ) at $37^{\circ} \mathrm{C}$ for $15 \mathrm{~min}$. The cell suspensions were mixed by inverting every $3-5$ min to fully expose cells to the probe. The cells were then washed three times with cell culture medium to remove the DCFH-DA that had not entered the cells. Finally, the fluorescence intensity of the cell reactive oxygen species (ROS) was detected by flow cytometry (Beckman Coulter, USA).

Supernatants were extracted from lung tissue homogenates and the culture media of $16 \mathrm{HBE}$ cells. Then, we determined the levels of SOD, CAT, GSH, and GSH-Px, in the lung tissues by using a range of commercial kits in accordance with the manufacturer's instructions (Jiancheng Bioengineering Institute, Nanjing, China).

\section{RT-PCR}

First, we used a TRIzol kit (Takara Bio, Dalian, China) to extract total RNA from lung tissues and cells. Next, we used an ABI 7500 PCR system (Applied Biosystems) to determine mRNA expression levels in cells and tissues. Quantification of mRNA expression in cells and lung tissue samples was performed using UltraSYBR Mixture (Takara Bio, Dalian, China). The following procedure was used for PCR cycling: initial denaturation $\left(95^{\circ} \mathrm{C}, 40 \mathrm{~s}\right)$, followed by 40 cycles of amplification $\left(95^{\circ} \mathrm{C}, 10 \mathrm{~s} ; 58^{\circ} \mathrm{C}, 10 \mathrm{~s} ; 72^{\circ} \mathrm{C}, 34 \mathrm{~s}\right)$, cooling cycle $\left(60^{\circ} \mathrm{C}, 15 \mathrm{~s}\right)$, and melting curve $\left(95^{\circ} \mathrm{C}, 15 \mathrm{~s} ; 60^{\circ} \mathrm{C}, 1 \mathrm{~min} ; 95^{\circ} \mathrm{C}, 15 \mathrm{~s}\right)$. GAPDH was used as an internal control and mRNA levels were calculated using the ${ }^{2-\Delta \Delta} \mathrm{Ct}$ method (relative) [13]. All primers were tested using a basic local alignment search tool to determine their selectivity. The primer sequences are shown in Table 1. 
Table 1

Primers for quantitative real-time PCR analysis.

\begin{tabular}{|c|c|c|}
\hline Gene & Primer sequence $\left(5^{\prime}-3^{\prime}\right)$ & $\operatorname{Tm}\left({ }^{\circ} \mathrm{C}\right)$ \\
\hline \multirow[t]{2}{*}{ Mouse IL-1 $\beta$} & Sense CGAGGCAGTATCACTCATTG & \multirow[t]{2}{*}{58} \\
\hline & Antisense CGTTGCTTGGTTC- TCCTTGT & \\
\hline \multirow[t]{2}{*}{ Mouse TNF- $a$} & Sense CAGACCCTCACACTCAGATCATCTT & \multirow[t]{2}{*}{58} \\
\hline & Antisense TCGTAGCAAACCACCAAGTGG & \\
\hline \multirow[t]{2}{*}{ Mouse KC } & Sense GCTGGGATTCACCTCAAGAA & \multirow[t]{2}{*}{58} \\
\hline & Antisense TGGGGACAAATTTTAGCATC & \\
\hline \multirow[t]{2}{*}{ Mouse TGF- $\beta_{1}$} & Sense TGAGTGGCTGTCTTTTGACG & \multirow[t]{2}{*}{58} \\
\hline & Antisense TCTCTGTGGAGCTGAAGCAA & \\
\hline \multirow[t]{2}{*}{ Mouse TLR4 } & Sense CTCACAACTTCAGTGGCTGGATTTA & \multirow[t]{2}{*}{58} \\
\hline & Antisense GTCTCCACAGCCACCAGATTCTC & \\
\hline \multirow[t]{2}{*}{ Mouse MyD88 } & Sense ATACCAACCCTTGCACCAAGTC & \multirow[t]{2}{*}{58} \\
\hline & Antisense TCAGGCTCCAAGTCAGCTCATC & \\
\hline \multirow[t]{2}{*}{ Mouse TRAF-6- } & Sense TTTGGCGTCGGAGACACTTG & \multirow[t]{2}{*}{58} \\
\hline & Antisense TCGCTTGAAGACTGGCTGGA & \\
\hline \multirow[t]{2}{*}{ Mouse NLRP3 } & Sense AGATTACCCGCCCGAGAAAG & \multirow[t]{2}{*}{58} \\
\hline & Antisense TCCCAGCAAACCCATCCACT & \\
\hline \multirow[t]{2}{*}{ Mouse GAPDH } & Sense AACTTTGGCATTGTGGAAGG & \multirow[t]{2}{*}{58} \\
\hline & Antisense AACTTTGGCATTGTGGAAGG & \\
\hline
\end{tabular}

Western blotting

Total proteins were extracted from cells and lung tissues using radioimmunoprecipitation (RIPA) lysis buffer kits (Boster Co. Ltd., CA). Protein extracts were then separated by $10 \%$ sodium dodecyl sulfatepolyacrylamide gel electrophoresis (SDS-PAGE) and transferred onto polyvinylidene fluoride (PVDF) membranes. Then, we used rapid blocking buffer (Beyotime, China) to block the membranes at room temperature for $15 \mathrm{~min}$ and then incubated the membranes overnight at $4^{\circ} \mathrm{C}$ with an appropriate concentration of each primary antibody (1: 200-1000, anti-TLR4, anti-MyD88, anti-TRAF-6, anti-NLRP3, anti-Erk1/2, anti-P38 and anti-GAPDH), respectively. The next morning, membranes were washed and incubated with secondary antibody (Cell Signaling Technology, Beverly, MA, USA) for $1 \mathrm{~h}$. Then, band densities were quantified using Image $\mathrm{J}$ software (Version 1.38e, NIH, Bethesda, MD) and normalized to their respective loading control. 


\section{Statistical analysis}

All statistical analysis was carried out with SPSS version 20.0 (SPSS Inc., Chicago, IL, USA) and GraphPad Prism 6.0 (GraphPad Software, La Jolla, CA, USA). Differences between the mean values of multiple groups were analyzed by one-way analysis of variance (ANOVA) followed by the StudentNewman-Keuls test. $P<0.05$ was statistically significant.

\section{Results}

PM2.5-induced lung inflammation and MyD88 expression in vivo

In this study, we investigated how exposure to PM2.5 induces airway inflammation and the expression of relevant signaling pathway proteins an animal model. First, we first investigated the effects of PM2.5 exposure on airway inflammation and the expression of MyD88 in lung tissues. As shown in Fig. 1, after 6 days of exposure to PM2.5, the lung tissue of experimental mice showed clear signs of serious damage, including infiltration by a large number of neutrophils and macrophages and edema of the alveolar septum (Fig. 1A). In addition, MyD88 protein was strongly expressed in epithelial cells at the medial trachea and in regions of lung tissue showing the infiltration of macrophages in the lung tissues (Fig. 1B).

SalB relieved PM2.5-induced lung inflammation in vivo

Analysis showed that exposure to PM2.5 induced a significant increase in the mRNA and protein expression levels of IL-1 $\beta$, TNF- $\alpha$, KC, and TGF- $\beta 1$ in lung tissues; these were reduced by treatment with SalB $(2.5,7.5$, and $15 \mathrm{mg} / \mathrm{mL})$ in a dose-dependent manner, or by treatment with ST2825, an MyD88 inhibitor $(5 \mathrm{mg} / \mathrm{mL})$, compared with model group (Fig. $2 A$ and B). In addition, there was a significant reduction in the concentrations of total leukocytes, macrophages, and neutrophils, in mice that inhaled SalB or ST2825 when compared with the model group (Fig. 2C). Pathological analysis showed that the inhalation of SalB or ST2825 alleviated alveolar septal edema and the influx of neutrophils and macrophages into the alveolar spaces (Fig. 2D and E). These observations provide preliminary evidence for SalB in the inhibition of acute airway inflammation induced by PM2.5.

SalB alleviated PM2.5-induced oxidative stress in vivo

Next, we investigated the effects of SalB inhalation on PM2.5-induced oxidative stress in vivo by analyzing lung tissues that had been harvested $24 \mathrm{~h}$ after the last exposure to PM2.5. Results showed that PM2.5 exposure induced a significant reduction in SOD, CAT, GSH, and GSH-Px levels in mouse lung tissues; these changes were alleviated, in a dose-dependent manner, by treatment with SalB $(2.5,7.5$, and $15 \mathrm{mg} / \mathrm{mL}$ ) or ST2825 (5 mg/mL) (Fig. 3). These observations revealed that SalB inhibited PM2.5induced acute oxidative stress.

SalB Inhibited the PM2.5-induced Expression of TLR4, MyD88, TRAF-6, and NLRP3 in vivo 
Next, we investigated the effects of SalB on the PM2.5-induced expression of potential signal targets in vivo by analyzing harvested lung tissues $24 \mathrm{~h}$ after the last exposure to PM2.5. These results showed that exposure to PM2.5 induced a significant increase in the mRNA and protein expression of TLR4, MyD88, TRAF-6, and NLRP3 in lung tissues; these expression levels were reduced, in a dose-dependent manner, by treatment with SalB $(2.5,7.5$, and $15 \mathrm{mg} / \mathrm{mL})$ or ST2825 $(5 \mathrm{mg} / \mathrm{mL})$ (Fig. 4A and B). These observations revealed that SalB inhibited PM2.5-induced acute airway inflammation and oxidative stress via the TLR4/MyD88/TRAF-6/NLRP pathway.

SalB reduced the PM2.5-induced expression of inflammatory cytokines and oxidative stress in vitro

To verify the role of SalB in vivo, we next investigated the effect of SalB on PM2.5-induced inflammation and oxidative stress in human bronchial epithelial cells. Exposure to PM2.5 at various concentrations $(25-200 \mu \mathrm{g} / \mathrm{mL})$ for $24 \mathrm{~h}$ caused a dose-dependent elevation in the levels of IL-1 $\beta$, TNF- $\mathrm{a}, \mathrm{IL}-8, \mathrm{IL}-6$ and TGF- $\beta 1$ protein (Fig. $5 \mathrm{~A}$ ). As shown in Fig. $5 \mathrm{~B}$, the inhalation of $2.5,5$ and $10 \mu \mathrm{M}$ of SalB resulted in a dose-dependent reduction in the protein levels of IL- $1 \beta$, TNF- $\alpha$, IL- 8 , IL- 6 and TGF- $\beta 1$. In addition, there was a dose-dependent reduction in ROS levels and an increase in the levels of SOD, CAT, GSH and GSH-Px following pre-treatment with SalB or ST2825 (Fig. 5C and D). Furthermore, the effects of $10 \mu \mathrm{M}$ SalB were similar to those of ST2825, an inhibitor of MYD88, at a concentration of $10 \mu \mathrm{M}$. These results are consistent with those observed in vivo.

Inflammation and oxidative stress were mediated in vitro by Erk1/2/P38 via the TLR4/MyD88/NLRP3 pathway

Next, we investigated the molecular basis of SalB with regards to its anti-inflammatory and antioxidant properties in response to PM2.5 in vitro. As shown in Fig. 6, both SalB and ST2825 significantly inhibited the expression of TLR4, MyD88, and TRAF- 6 , as well as phosphorylation of their downstream signals ERK1/2 and P38 (Fig. 6A and B). Finally, we found that SalB reduced the expression of the NLRP3 inflammasome in a dose-dependent manner (Fig. 6C). These results are consistent with those observed in vivo. These data suggest that the potential effects of SalB on PM2.5-induced airway inflammation and oxidative stress were mainly mediated via the TLR4/MyD88/NLRP signaling pathway.

\section{Discussion}

In this study, we first showed that PM2.5-induced inflammatory cell infiltration in lung tissue is related to the increased expression levels of MyD88 protein, thus suggesting that MyD88 may regulate PM2.5induced acute airway inflammation. Inhalation of a MyD88 inhibitor (ST2825) and SalB significantly reduced PM2.5-induced acute airway inflammation and oxidative stress, reduced the release of inflammatory cytokines, and reversed the increase of ROS and the reduction of antioxidant factors in lung tissue and in human epithelial cells. Furthermore, inhalation of the MyD88 inhibitor and SalB also inhibited the TLR4/MyD88/TRAF-6/NLRP3 pathway, as well as the downstream pathway (ERK1/2 and P38) (Fig. 7). 
Worldwide, it is estimated that more than 2 million people die each year from lung and respiratory damage caused by air pollution [14]. Of these, approximately 2.1 million and 470,000 deaths were estimated to have been caused by fine particulate matter (PM) and ozone, respectively $[14,15]$. Many studies have reported that particulate matter exposure is the root cause of a variety of health problems, including premature death in patients with lung or heart disease, respiratory irritation, cough, breathing difficulties, the acute exacerbation of asthma and chronic obstructive pulmonary disease, reduced lung function, heart attacks, and irregular heart rhythms $[16,17]$. Increases of $10 \mu \mathrm{g}$ per cubic meter of PM2.5 and $10 \mathrm{ppb}$ of ozone have been associated with a $7.3 \%$ and $1.1 \%$ increase in mortality rate, respectively. ${ }^{18}$ When analysis was restricted to person-years of exposure to a PM2.5 concentration of less than $12 \mu \mathrm{g}$ per cubic meter, and an ozone concentration of less than 50 ppb, the same increases in PM2.5 and ozone were associated with an increased risk of death by $13.6 \%$ and $1.0 \%$, respectively [18]. Although air pollution can cause respiratory diseases, there are no specific drugs to prevent and treat these conditions. Therefore, there is an urgent need to identify methods to prevent and treat these diseases. In China, there are many natural herbal medicines, and traditional Chinese medicines, that can be used to treat respiratory inflammation; these are usually safe and effective. Therefore, we are particularly interested in studying the effect of SalB on PM2.5-induced airway inflammation and oxidative stress. Air pollution (PM2.5) first affects the health of the respiratory tract. Since the respiratory tract is an open organ, air pollution, and especially PM2.5 particles, can readily damage the respiratory system by lowering the defenses of the airway epithelium and by altering immune responses. Airway epithelial cells are the first line of defense against airborne irritants, pollutants, and infectious agents [19]. Therefore, our first consideration was to strengthen the ability of the epithelial cells as a barrier. In the present study, we decided to use the inhalation route rather than systemic administration (oral or injection) because it has been proven that inhalation is the best route of delivery for respiratory diseases such as asthma and chronic obstructive pulmonary disease (COPD). The direct delivery of a drug to the target organ (the lung tissue) results in high local concentrations of the drug in the target organ and a highly effective form of treatment; in contrast, only low concentrations of the drug reach organs in other parts of the body, thus reducing the incidence of adverse reactions [20].

Over recent years, researchers have attempted to prevent and control the cellular and organ damage caused by PM2.5. Some researchers have shown that some natural compounds, and traditional Chinese medicines, can protect the cell and organ damage induced by PM2.5 both in vitro and in vivo, including isovitexin [21], astaxanthin [22], curcumin [23], astragalus [24], codonopsis pilosula [24], ophiopogonin [25], triptolide [26], astragaloside IV [27], resveratrol [28], and Ientinan [29]. All of these studies were carried out in vivo; drugs were administered systematically, by either oral or injection routes. In the present study, we proved for the first time that the inhalation of SalB can significantly reduce the PM2.5-induced increase in the numbers of neutrophils and macrophages in BALF, decrease the infiltration of neutrophils and macrophages in lung tissue, and markedly reversed the levels of SOD, CAT, GSH, and GSH-PX.

Treatment with SalB reduced the PM2.5-induced increase in the mRNA and protein expression levels of IL$1 \beta$, TNF- $\alpha, \mathrm{KC}$, and TGF- $\beta 1$ in mouse lung tissues and did so in a dose-dependent manner. Our results also showed that exposure to PM2.5 induced a significant increase in the mRNA and protein expression levels 
of TLR4, MyD88, TRAF-6, and NLRP3, in mouse lung tissues; these effects were reduced by SalB treatment in a dose-dependent manner. Next, we tried to verify the in vivo effect of SalB and found that PM2.5 stimulated an increase in the release of inflammatory cytokines and a reduction in the levels of antioxidant factors in human bronchial epithelial (16HBE) cells. SalB was also shown to inhibit the release of IL-1 $\beta$, TNF- $\alpha$, IL-8, and TGF- $\beta 1$ in a dose-dependent manner, and reverse the reduction of SOD, CAT, GSH, and GSH-Px levels. Consistent with our in vivo results, SalB also significantly inhibited the expression levels of TLR4, MyD88 and TRAF-6 proteins. Further in vitro studies on the downstream signaling pathways (TLR4/MyD88/TRAF-6) showed that SalB could significantly reduce the phosphorylation of ERK1/2 and P38. An inhibitor of MyD88 (ST2825) was used consistently as a control drug for all in vivo and in vitro experiments. Previous studies have shown that PM2.5 promotes plaque vulnerability at different stages of atherosclerosis, the formation of foam cells [6], lung injury [27], and exacerbates allergic inflammation in the murine lung [30] via the TLR4/MyD88/NFKB pathway. Previous research, involving MyD88 $8^{-/-}$mice, showed that the exacerbation of PM2.5-enhanced ovalbumin allergic inflammation was significantly inhibited [31]. Furthermore, PM2.5-exposure has been shown to trigger increased expression of proinflammatory mediators (IL-6, IL-12, and MCP-1) and attenuate the influx of neutrophils into the pulmonary alveoli [32]. In addition, thew MyD88 inhibitor LM9 has been shown to prevent the pathogenesis of atherosclerosis, accompanied by reduced vascular inflammation and oxidative stress in $\mathrm{ApoE}^{-/-}$mice fed upon a high-fat diet [33]. These previous studies highlighted the translational role of MyD88 as a potential therapeutic target for the treatment of PM2.5-triggered airway inflammation and oxidative stress. In the present study, we proved, for the first time, that the mechanisms underlying the action of SalB are similar to those underlying the effects of the MyD88 inhibitor ST2825, thus suggesting that SalB is a natural compound that can act in the same way as the MyD88 inhibitor, the detailed action mechanism of SalB will be further studied by us.

\section{Conclusion}

Here, we demonstrate that the inhibition of the TLR4/MyD88/NLRP3 pathway is an effective means of treating inflammation and oxidative stress. Treatment with a MyD88 inhibitor (ST2825) and SalB significantly prevented and controlled PM2.5-triggered airway inflammation and oxidative stress. The inhalation of SalB allowed direct targeting of the drug directly to the target organs, thus improving its bioavailability, enhancing its efficacy, and reducing adverse systemic effects during the treatment of PM2.5-induced acute airway inflammation.

\section{Abbreviations}

\section{TLR4}

Toll-like receptor 4

\section{MyD88}

myeloid differentiation primary response 88

TRAF-6 
TNF receptor associated factor 6

NLRP3

NOD-like receptor protein 3

Elisa

enzyme-linked immunosorbent assays

\section{RT-PCR}

real-time quantitative polymerase chain reaction

IL

Interleukin

TNF

tumor necrosis factor

KC

keratinocyte

TGF

transforming growth factor

SOD

superoxide dismutase

CAT

catalase

GSH

glutathione

GSH-PX

glutathione peroxidase

ROS

reactive oxygen species

Erk1/2

extracellular signal regulated kinase 1/2

P38

P38 MAP kinase

DCFH-DA

2',7'-Dichlorodihydrofluorescein diacetate

HPLC

high-performance liquid chromatography

FBS

fetal bovine serum

BALF

bronchoalveolar lavage fluid

PBS

phosphate buffer solution

BSA 
bovine serum albumin

H\&E

hematoxylin-eosin

IHC

Immunohistochemical

RIPA

radioimmunoprecipitation

SDS-PAGE

sodium dodecyl sulfate-polyacrylamide gel electrophoresis

PVDF

polyvinylidene fluoride

\section{Declarations}

\section{Ethics declarations}

\section{Ethics approval and consent to participate}

This study was carried out in accordance with the recommendations of Guide for the Care and Use of Laboratory Animals of Zhejiang University, Zhejiang University Animal Care and Use Committee. The protocol was approved by the Zhejiang University Animal Care and Use Committee.

\section{Availability of data and materials}

The analyzed datasets generated during the study are available from the corresponding author on reasonable request.

\section{Competing interests}

The authors have no financial conflicts of interest.

\section{Funding}

This work was supported by the Natural Science Foundation of Zhejiang Province, China [Grant number: LY19H310006] for Yan Guan; and the National Natural Science Foundation of China [Grant number: 81872876] for Yan Guan and Qiangmin Xie.

\section{Contributions}


YG and QX designed the study and drafted the manuscript. YG, CL, and LK performed the experiments and data analysis. All authors have read and approved the final submitted paper.

\section{Acknowledgements}

Thanks to the researchers at the Zhejiang Respiratory Drugs Research Laboratory of State Food and Drug Administration of China for their generous assistance with the experiments.

\section{Author details}

1. Affiliated Sir Run Run Shaw Hospital, Zhejiang University School of Medicine, Hangzhou, 310020, People's Republic of China.

2. Zhejiang Respiratory Drugs Research Laboratory of State Food and Drug Administration of China, Zhejiang University School of Medicine, Hangzhou, 310058, People's Republic of China.

3. The Children's Hospital, Zhejiang University School of Medicine, National Clinical Research Center for Child Health, Hangzhou, 310052, People's Republic of China.

\section{References}

1. Mukherjee A, Agrawal M. A Global Perspective of Fine Particulate Matter Pollution and Its Health Effects. Rev Environ Contam Toxicol. 2018;244:5-51.

2. Kim KH, Kabir E, Kabir S. A review on the human health impact of airborne particulate matter. Environ Int. 2015;74:136-43.

3. Xu Z, Ding W, Deng X. PM 2.5 , Fine Particulate Matter: A Novel Player in the Epithelial-Mesenchymal Transition? Front Physiol. 2019;10:1404.

4. Jia H, Liu Y, Guo D, He W, Zhao L, Xia S. PM2.5-induced pulmonary inflammation via activating of the NLRP3/caspase-1 signaling pathway. Environ Toxicol. 2021;36(3):298-307.

5. Borthwick LA. The IL-1 cytokine family and its role in inflammation and fibrosis in the lung. Semin Immunopathol. 2016;38(4):517-34.

6. Geng J, Liu H, Ge P, Hu T, Zhang Y, Zhang X, Xu B, Wang B, Xie J. PM2.5 promotes plaque vulnerability at different stages of atherosclerosis and the formation of foam cells via TLR4/MyD88/NFkB pathway. Ecotoxicol Environ Saf. 2019;176:76-84.

7. Wu Y, Xu S, Tian XY. The Effect of Salvianolic Acid on Vascular Protection and Possible Mechanisms. Oxid Med Cell Longev. 2020;2020:5472096.

8. Xiao Z, Liu W, Mu YP, Zhang H, Wang XN, Zhao CQ, Chen JM, Liu P. Pharmacological Effects of Salvianolic Acid B Against Oxidative Damage. Front Pharmacol. 2020;11:572373.

9. Zhao R, Liu X, Zhang L, Yang H, Zhang Q. Current Progress of Research on Neurodegenerative Diseases of Salvianolic Acid B. Oxid Med Cell Longev. 2019;2019:3281260. 
10. Guan Y, Zhu JP, Shen J, Jia YL, Jin YC, Dong XW, Xie QM. Salvianolic acid B improves airway hyperresponsiveness by inhibiting MUC5AC overproduction associated with Erk1/2/P38 signaling. Eur J Pharmacol. 2018;824:30-9.

11. Gao DY, Han LM, Zhang LH, Fang XL, Wang JX. Bioavailability of salvianolic acid B and effect on blood viscosities after oral administration of salvianolic acids in beagle dogs. Arch Pharm Res. 2009;32(5):773-9.

12. Wu YT, Chen YF, Hsieh YJ, Jaw I, Shiao MS, Tsai TH. Bioavailability of salvianolic acid B in conscious and freely moving rats. Int J Pharm. 2006;326(1-2):25-31.

13. Zhang S, Zhang W, Zeng X, Zhao W, Wang Z, Dong X, Jia Y, Shen J, Chen R, Lin X. Inhibition of Rac1 activity alleviates PM2.5-induced pulmonary inflammation via the AKT signaling pathway. Toxicol Lett. 2019;310:61-9.

14. Livak KJ, Schmittgen TD. Analysis of relative gene expression data using real-time quantitative PCR and the 2(-Delta Delta C(T)) Method. Methods. 2001;25(4):402-8.

15. Shah AS, Lee KK, McAllister DA, Hunter A, Nair H, Whiteley W, Langrish JP, Newby DE, Mills NL. Short term exposure to air pollution and stroke: systematic review and meta-analysis. BMJ. 2015;350:h1295.

16. Xia R, Zhou G, Zhu T, Li X, Wang G. Ambient Air Pollution and Out-of-Hospital Cardiac Arrest in Beijing, China. Int J Environ Res Public Health. 2017;14(4):423.

17. Shamsollahi HR, Jahanbin B, Rafieian S, Yunesian M. Particulates induced lung inflammation and its consequences in the development of restrictive and obstructive lung diseases: a systematic review. Environ Sci Pollut Res Int. 2021;28(20):25035-50.

18. Grzywa-Celińska A, Krusiński A, Milanowski J. Smoging kills. Effects of air pollution on human respiratory system. Ann Agric Environ Med. 2020;27(1):1-5.

19. Di Q, Wang Y, Zanobetti A, Wang Y, Koutrakis P, Choirat C, Dominici F, Schwartz JD. Air Pollution and Mortality in the Medicare Population. N Engl J Med. 2017;376(26):2513-22.

20. Yang L, Li C, Tang X. The Impact of $\mathrm{PM}_{2.5}$ on the Host Defense of Respiratory System. Front Cell Dev Biol. 2020;8:91.

21. Borghardt JM, Kloft C, Sharma A. Inhaled Therapy in Respiratory Disease: The Complex Interplay of Pulmonary Kinetic Processes. Can Respir J. 2018;2018:2732017.

22. Chowjarean V, Prueksasit T, Joyjamras K, Chanvorachote P. Isovitexin Increases Stem Cell Properties and Protects Against PM2.5 in Keratinocytes. In vivo. 2019;33(6):1833-41.

23. Kim RE, Shin CY, Han SH, Kwon KJ. Astaxanthin Suppresses. PM2.5-Induced Neuroinflammation by Regulating Akt Phosphorylation in BV-2 Microglial Cells. Int J Mol Sci. 2020;21(19):7227.

24. Huang K, Shi C, Min J, Li L, Zhu T, Yu H, Deng H. Study on the Mechanism of Curcumin Regulating Lung Injury Induced by Outdoor Fine Particulate Matter (PM2.5). Mediators Inflamm. 2019;2019:8613523. 
25. Chu X, Liu XJ, Qiu JM, Zeng XL, Bao HR, Shu J. Effects of Astragalus and Codonopsis pilosula polysaccharides on alveolar macrophage phagocytosis and inflammation in chronic obstructive pulmonary disease mice exposed to PM2.5. Environ Toxicol Pharmacol. 2016;48:76-84.

26. Wang Y, Li D, Song L, Ding H. Ophiopogonin D attenuates PM2.5-induced inflammation via suppressing the AMPK/NF-KB pathway in mouse pulmonary epithelial cells. Exp Ther Med. 2020;20(6):139.

27. Wan Q, Liu Z, Yang M, Deng P, Tang N, Liu Y. Triptolide ameliorates fine particulate matter-induced podocytes injury via regulating NF-KB signaling pathway. BMC Mol Cell Biol. 2020;21(1):4.

28. Wu Y, Xiao W, Pei C, Wang M, Wang X, Huang D, Wang F, Wang Z. Astragaloside IV alleviates PM2.5induced lung injury in rats by modulating TLR4/MyD88/NF-KB signalling pathway. Int Immunopharmacol. 2021;91:107290.

29. Ren F, Huang Y, Tao Y, Ji C, Aniagu S, Jiang Y, Chen T. Resveratrol protects against PM2.5-induced heart defects in zebrafish embryos as an antioxidant rather than as an AHR antagonist. Toxicol Appl Pharmacol. 2020;398:115029.

30. Qi H, Liu Y, Wang N, Xiao C. Lentinan Attenuated the PM2.5 Exposure-Induced Inflammatory Response, Epithelial-Mesenchymal Transition and Migration by Inhibiting the PVT1/miR-199a5p/caveolin1 Pathway in Lung Cancer. DNA Cell Biol. 2021;40(5):683-93.

31. He M, Ichinose T, Yoshida Y, Arashidani K, Yoshida S, Takano H, Sun G, Shibamoto T. Urban PM2.5 exacerbates allergic inflammation in the murine lung via a TLR2/TLR4/MyD88-signaling pathway. Sci Rep. 2017;7(1):11027.

32. He M, Ichinose T, Yoshida S, Ito T, He C, Yoshida Y, Arashidani K, Takano H, Sun G, Shibamoto T. PM2.5-induced lung inflammation in mice: Differences of inflammatory response in macrophages and type II alveolar cells. J Appl Toxicol. 2017;37(10):1203-18.

33. Chen T, Luo W, Wu G, Wu L, Huang S, Li J, Wang J, Hu X, Huang W, Liang G. A novel MyD88 inhibitor LM9 prevents atherosclerosis by regulating inflammatory responses and oxidative stress in macrophages. Toxicol Appl Pharmacol. 2019;370:44-55.

\section{Figures}


A

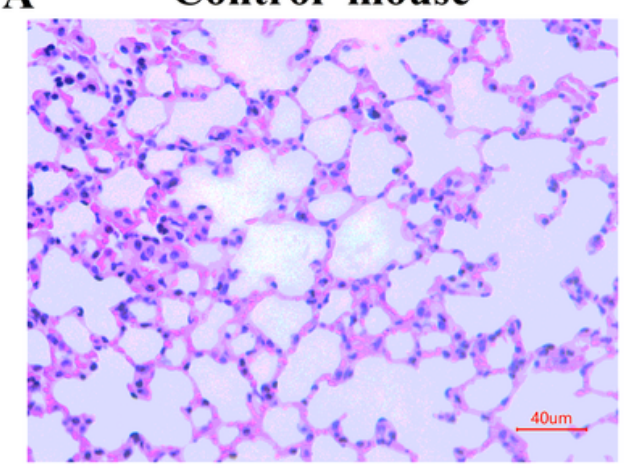

H\&E for inflammation

B

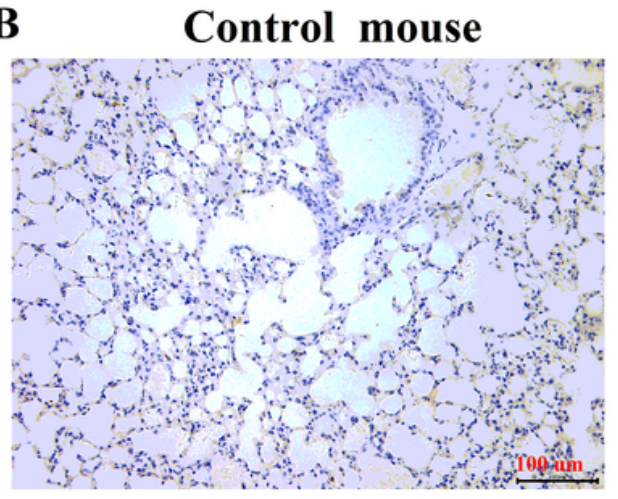

\section{IHC for MyD88 expression}

PM2.5 expose to mouse

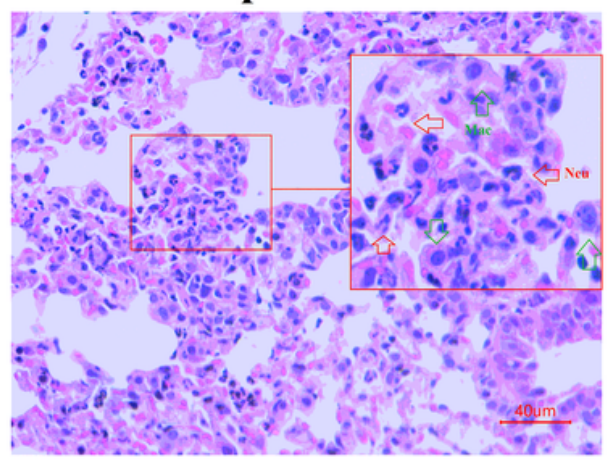

PM2.5 expose to mouse

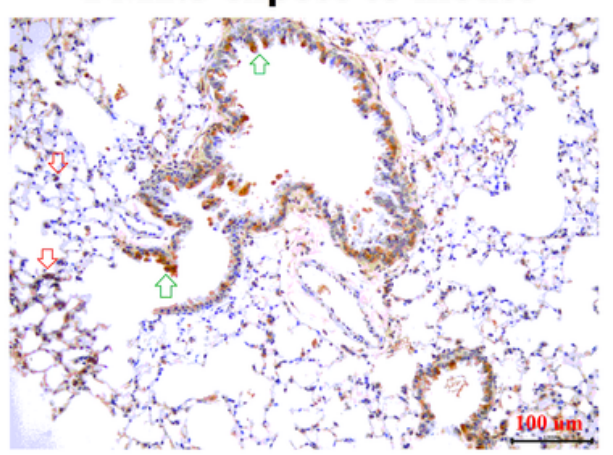

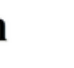

Figure 1

PM2.5 induced lung inflammation and upregulated MyD88 in vivo. (A) A representative image of lung inflammation (the infiltration of numerous neutrophils and macrophages) in lung tissues stained with hematoxylin-eosin. (B) The expression of MyD88; lung tissues were stained by immunohistochemistry. Data are expressed as mean \pm S.E.M.; $n=6 /$ group. \#\#\#P $<0.001$ compared with the control group. 

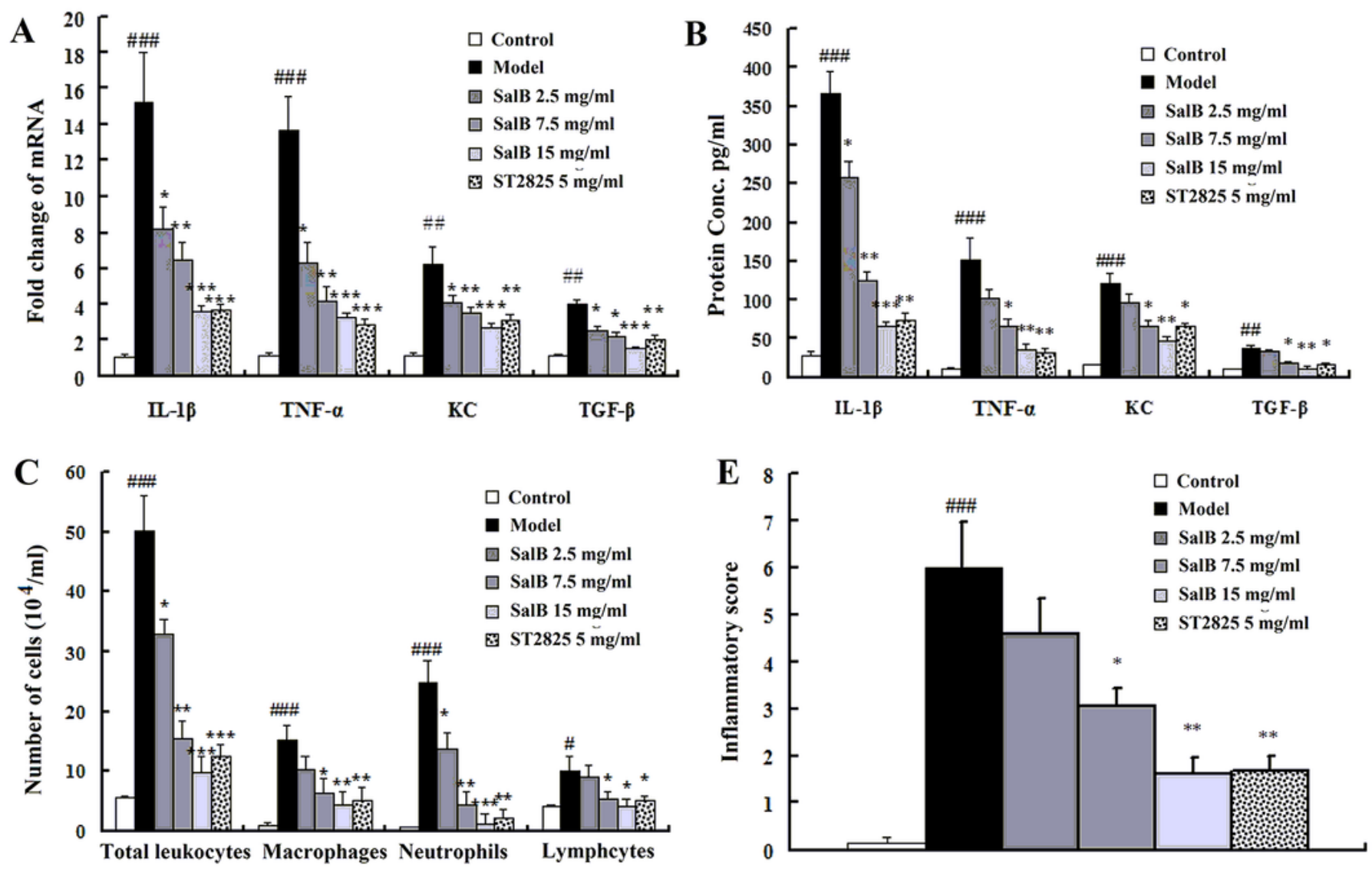

D
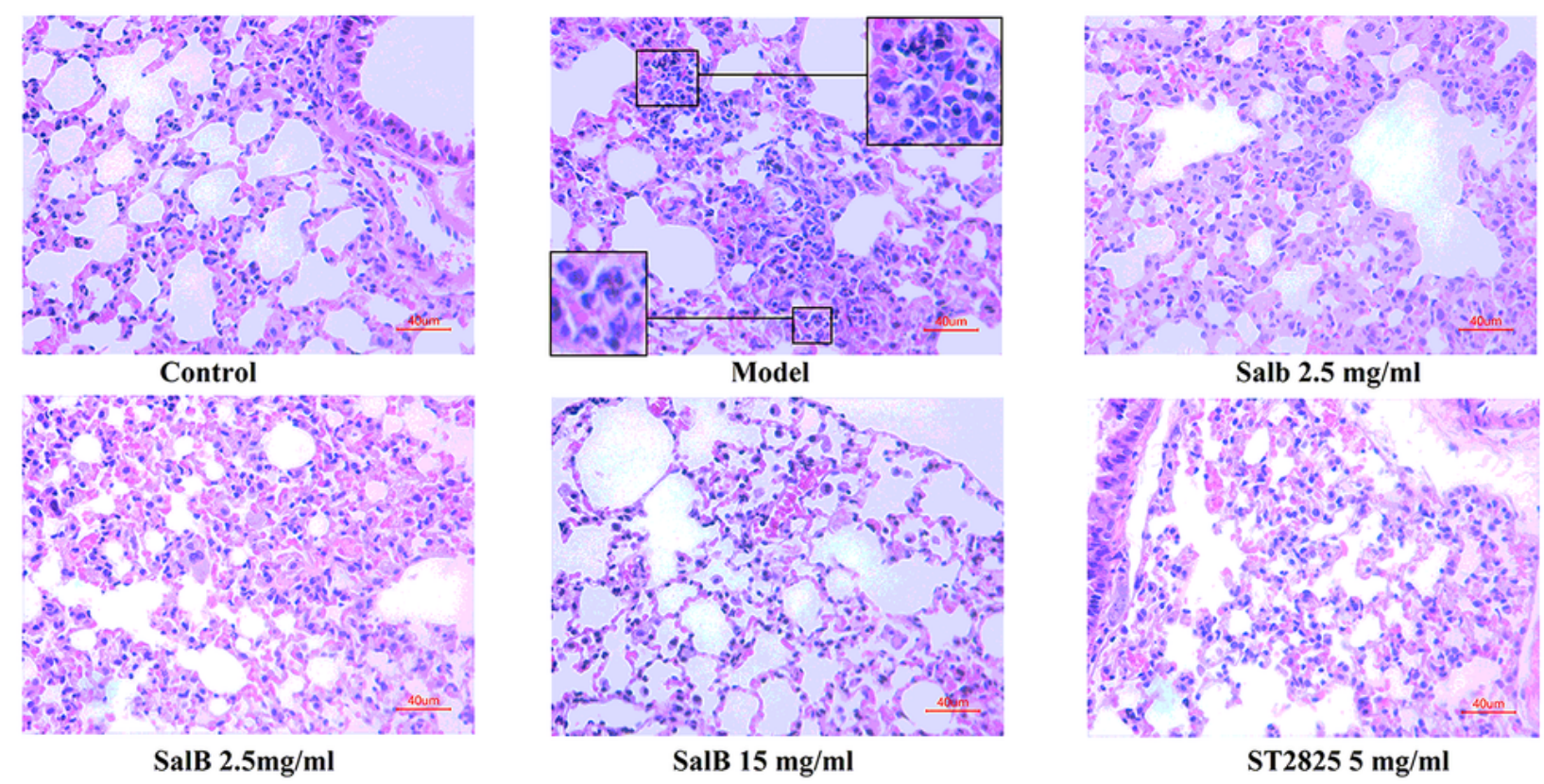

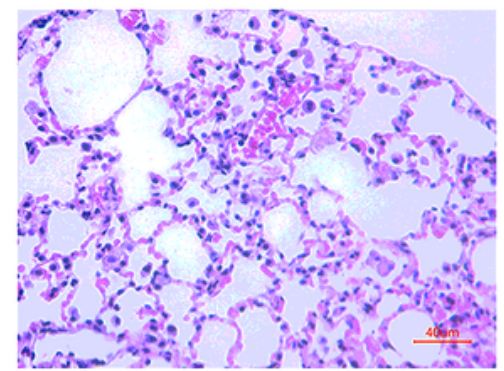

SalB $15 \mathrm{mg} / \mathrm{ml}$

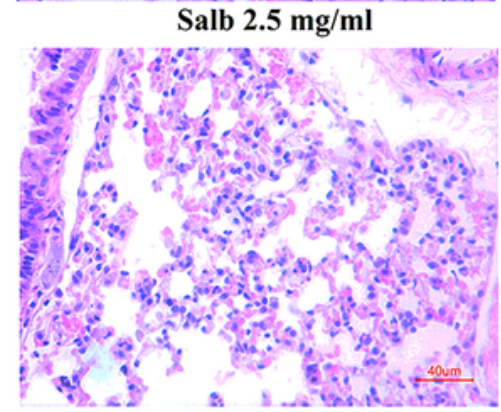

$\mathrm{ST} 28255 \mathrm{mg} / \mathrm{ml}$

\section{Figure 2}

The effects of SalB on PM2.5-induced lung inflammation in vivo. ( $A$ and $B$ ) Lung tissue homogenates were prepared for mRNA and protein assays. The expression levels of IL-1 $\beta$, TNF- $a, K C$ and TGF- $\beta 1$ mRNA and protein were measured by Q-PCR and ELISA. (C) The number of total leukocytes, neutrophils, macrophages, and lymphocytes in BALF. (D) Representative images of inflammatory cells infiltrating into lung tissues, as demonstrated by H\&E staining. (E) Semi-quantitative score analysis for the infiltration of 
pulmonary inflammatory cells and injury. Data are expressed as mean \pm S.E.M.; $n=10 /$ group of two independent experiments. \#P $<0.05$, \#\#P $<0.01$, and \#\#\#P<0.001 compared with the control group, *P $<$ 0.05 , ${ }^{\star *} \mathrm{P}<0.01$, and ${ }^{\star \star *} \mathrm{P}<0.001$ compared with the model group (exposure to $\mathrm{PM} 2.5$ ).
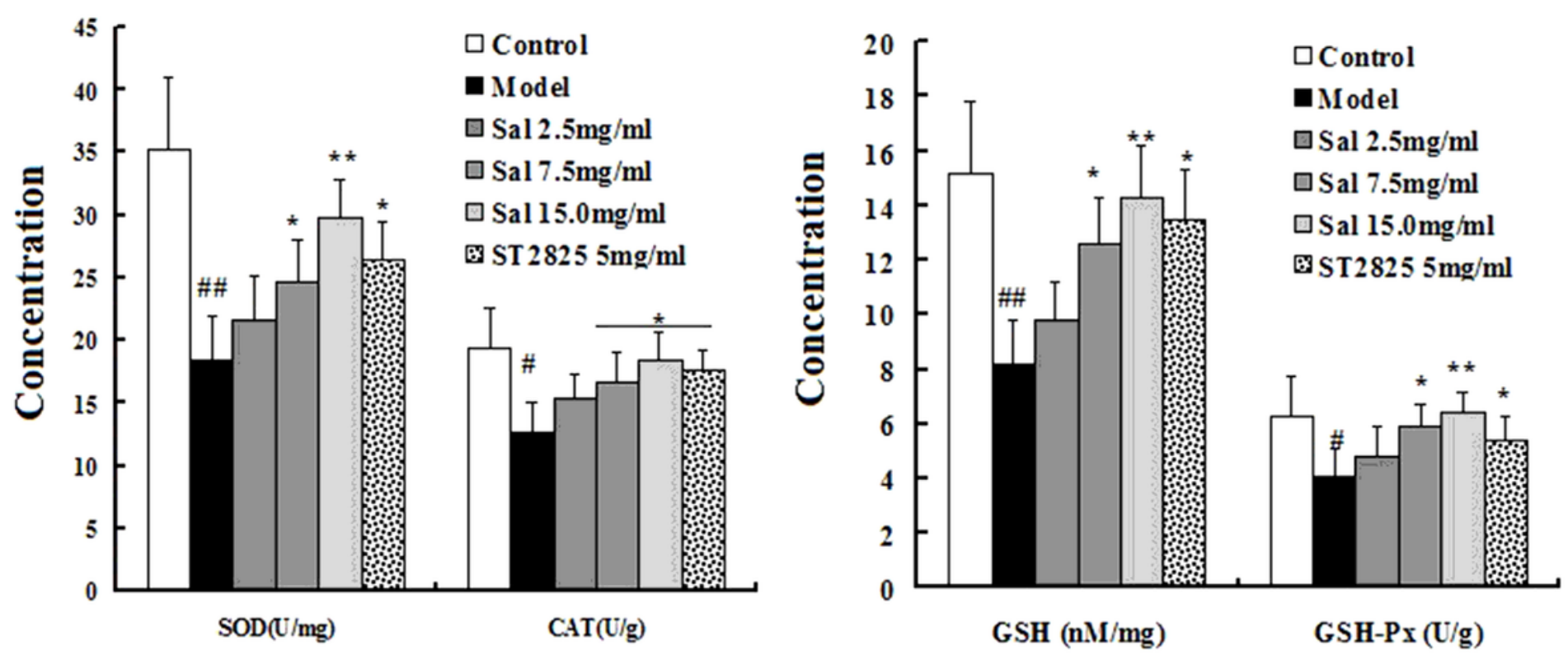

Figure 3

Effects of SalB on PM2.5-induced oxidative stress in vivo. Lung tissues were harvested $24 \mathrm{~h}$ after the final exposure to PM2.5. We detected the levels of SOD, CAT, GSH and GSH-Px in the supernatant of lung tissue homogenates. Data are expressed as mean \pm S.E.M.; $n=10$ /group of two independent experiments. $\# \mathrm{P}<0.05$ and \#\#P $<0.01$ compared with the control group, ${ }^{*} \mathrm{P}<0.05$ and ${ }^{*} \mathrm{P}<0.01$ compared with the model group. 


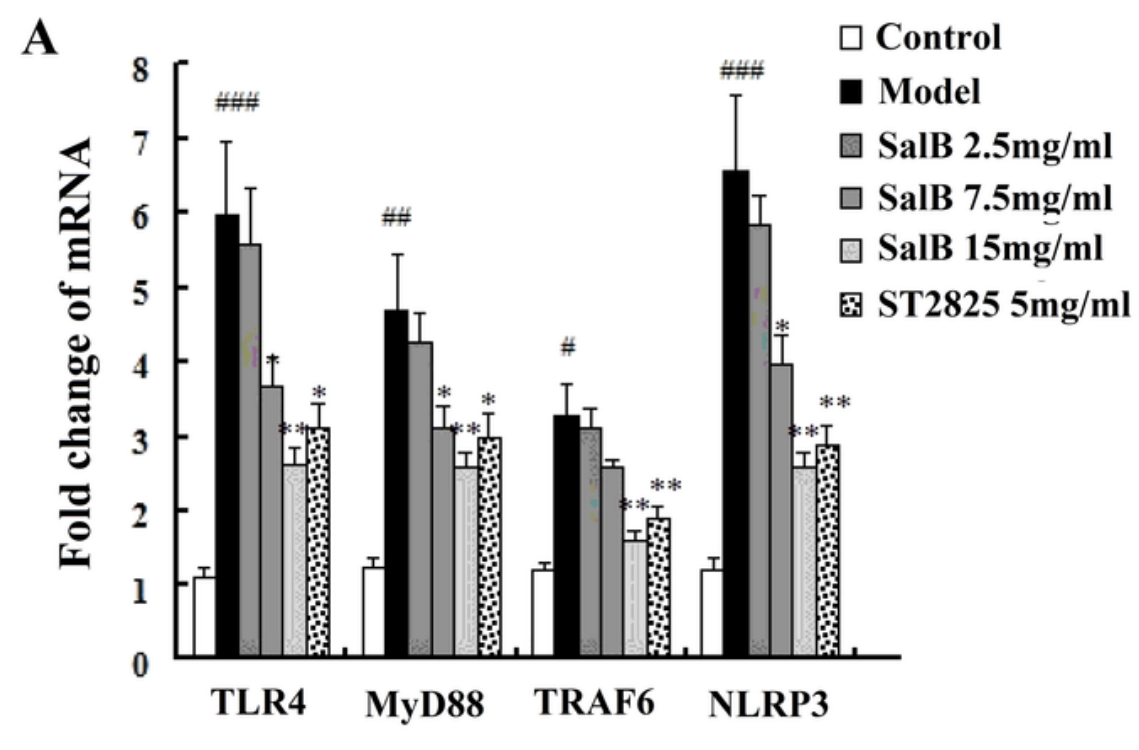

B

Control Model Sal 2.5mg Sal 7.5mg Sal $15 \mathrm{mg}$ ST2825 5mg

TLR4

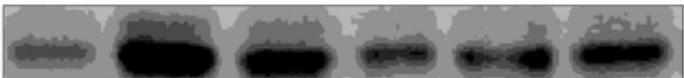

MyD88

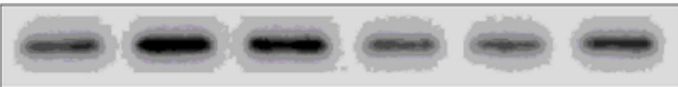

TRAF6

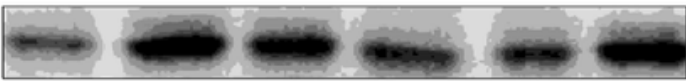

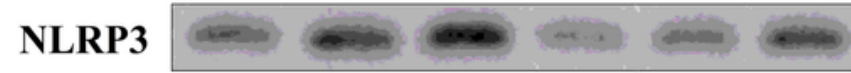
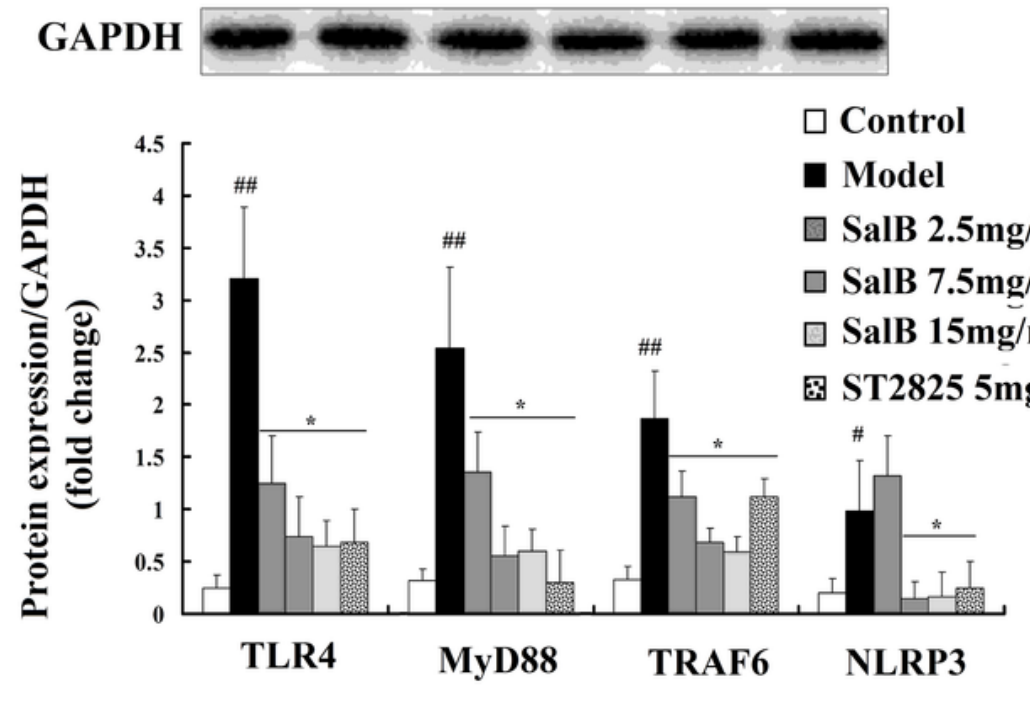

Figure 4

Effects of SalB on the PM2.5-induced expression of TLR4, MyD88, TRAF-6, and NLRP3 mRNA and protein in vivo. (A) The mRNA expression levels of TLR4, MyD88, TRAF- 6 and NLRP3 were detected by RT-PCR ( $\mathrm{n}$ $=6$ per group). Data represent means \pm S.E.M. from three independent experiments. (B) The expression levels of TLR4, MyD88, TRAF-6 and NLRP3 protein were assessed by western blotting ( $n=3 /$ group). Data 
represent mean \pm S.E.M from three independent experiments. \#P $<0.05$, \#\#P $<0.01$, and \#\#\#P 0.001 compared with the control group, ${ }^{*} \mathrm{P}<0.05$ and $* * \mathrm{P}<0.01$ compared with the model group.
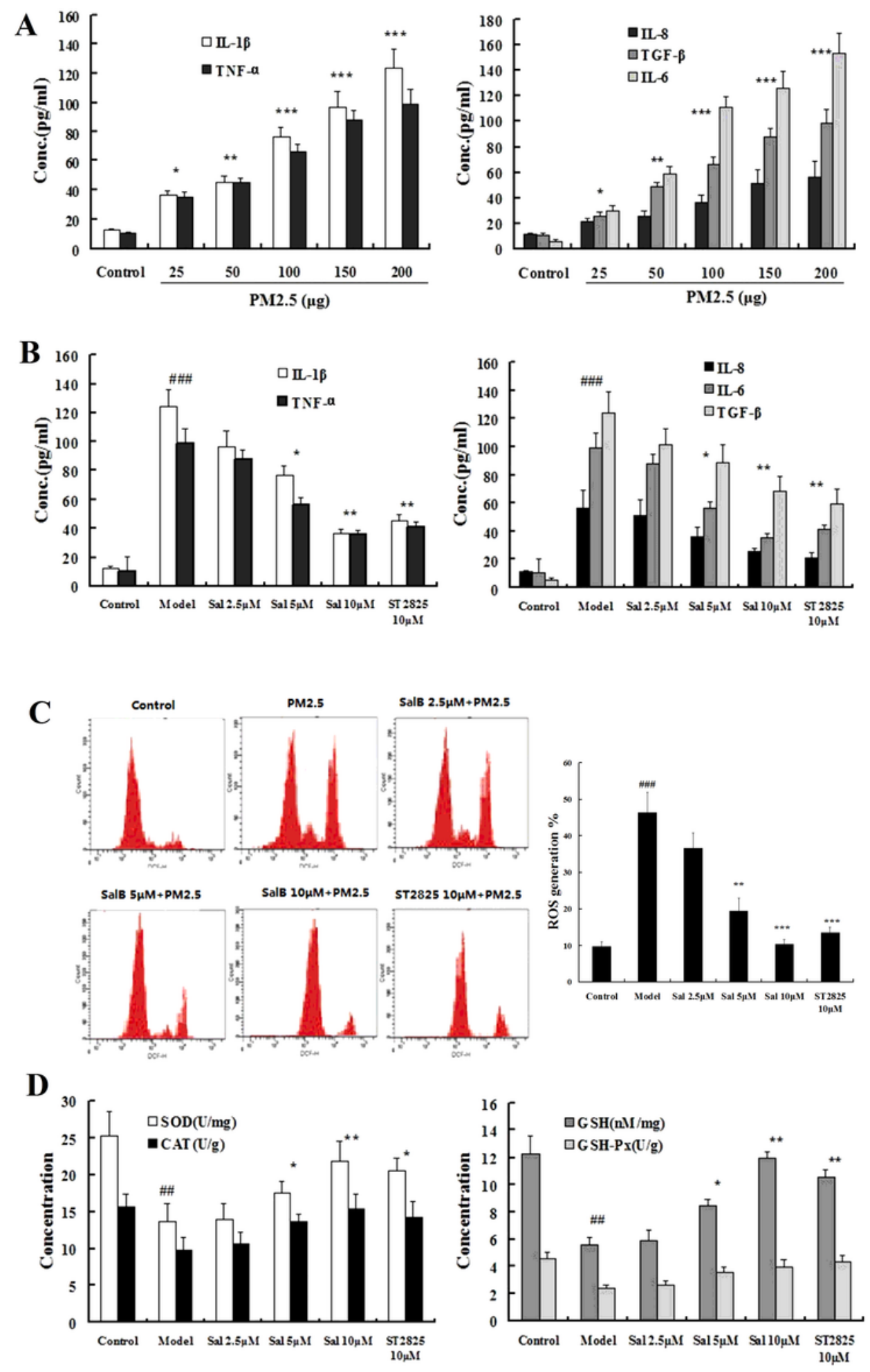

Figure 5

Effects of SalB on PM2.5-induced inflammatory cytokines and oxidative stress in vitro. (A) Human bronchial epithelial (16HBE) cells were exposed to PM2.5 at various concentrations $(25-200 \mu \mathrm{g} / \mathrm{mL})$ for 24 h. PM2.5 caused a dose-dependent elevation in the levels of IL-1 $\beta$, TNF- $a$, IL-8, IL- 6 and TGF- $\beta 1$ 
proteins. (B) Treatment with SalB resulted in a dose-dependent reduction in IL-1 $\beta$, TNF-a, IL-8, IL-6, and TGF- $\beta 1$ protein. (C) Treatment with SalB resulted in a dose-dependent reduction in ROS. (D) Treatment with SalB resulted in a dose-dependent increase in the levels of SOD, CAT, GSH and GSH-Px. Data are expressed as mean \pm S.E.M.; $n=6$ /group of three independent experiments. \#P<0.05, \#\#P<0.01, and $\# \# \# P<0.001$ compared with the control group; ${ }^{*} \mathrm{P}<0.05$ and $* * \mathrm{P}<0.01$ compared with the model group.

A

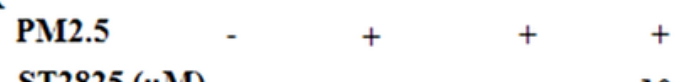

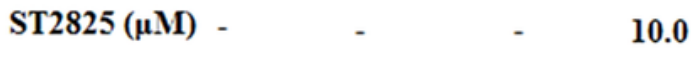

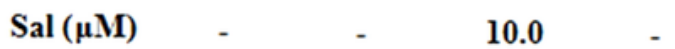
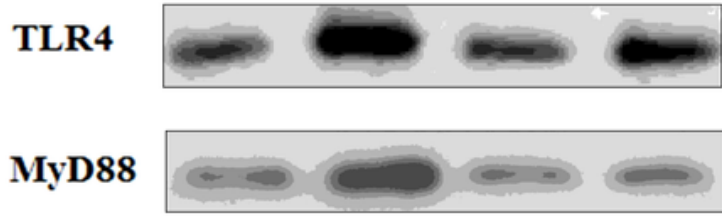

TRAF6

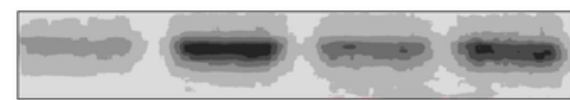

GAPDH

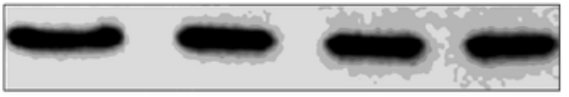

B

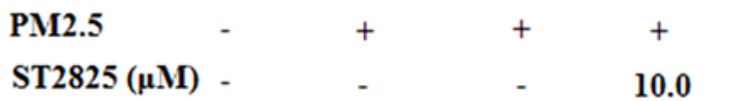

$\mathrm{Sal}(\mu \mathrm{M}) \quad-\quad-10.0 \quad-$

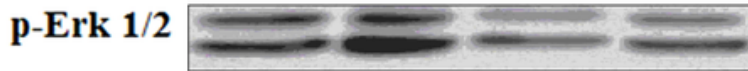

Erk 1/2
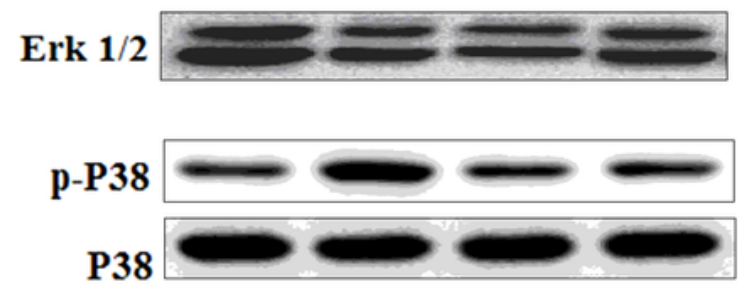

GAPDH
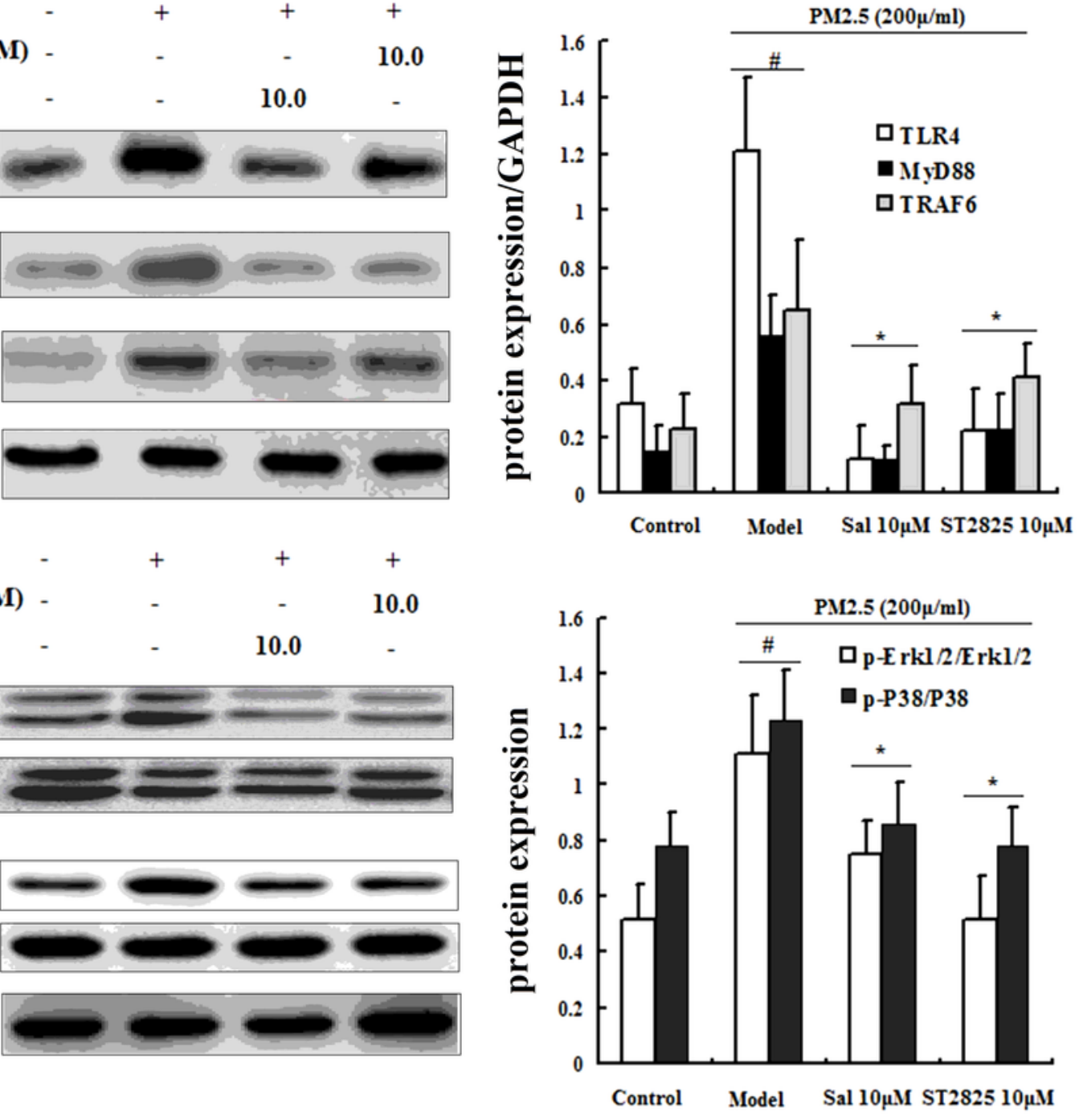

C
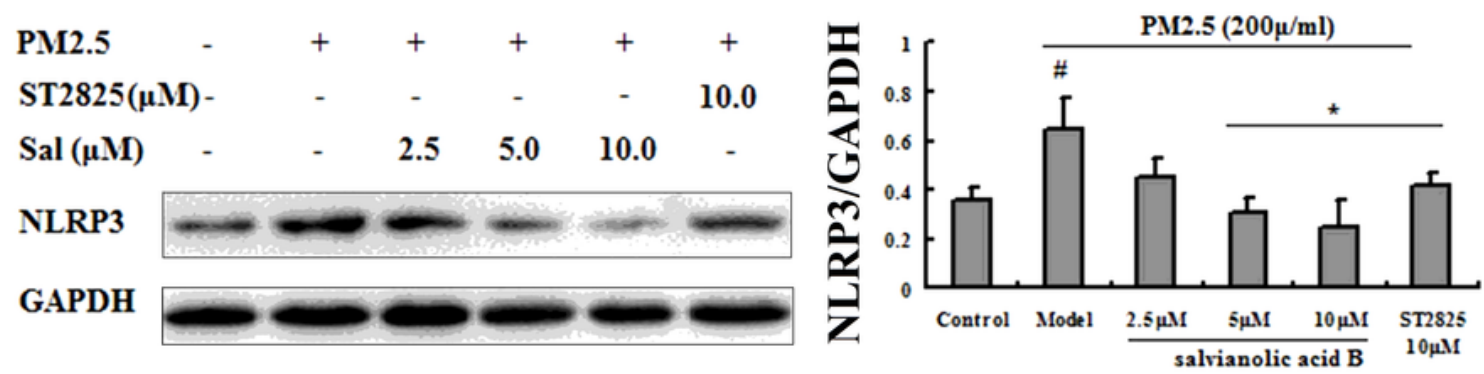

Figure 6 
Inhibiting the expression of the TLR4/MyD88/TRAF-6 pathway suppressed the phosphorylation of their downstream signals (ERK1/2 and P38) in 16HBE cells. 16HBE cells were pretreated with $10 \mu \mathrm{M}$ SalB or ST2825 for $0.5 \mathrm{~h}$ prior to exposure to PM2.5 $(200 \mu \mathrm{g} / \mathrm{mL})$ for $0.5 \mathrm{~h}$. Cell lysates were then immunoprecipitated. (A) The expression levels of TLR4, MyD88 and TRAF-6. (B) The phosphorylation of ERK1/2 and P38. (C) Treatment with SalB reduced the expression of the NLRP3 inflammasome in a dosedependent manner. Data represent mean \pm S.E.M. from three independent experiments. \#P $<0.05$ compared with control group (PM2.5 untreated), ${ }^{\star} \mathrm{P}<0.01$, compared with the model group (exposure to PM2.5). 


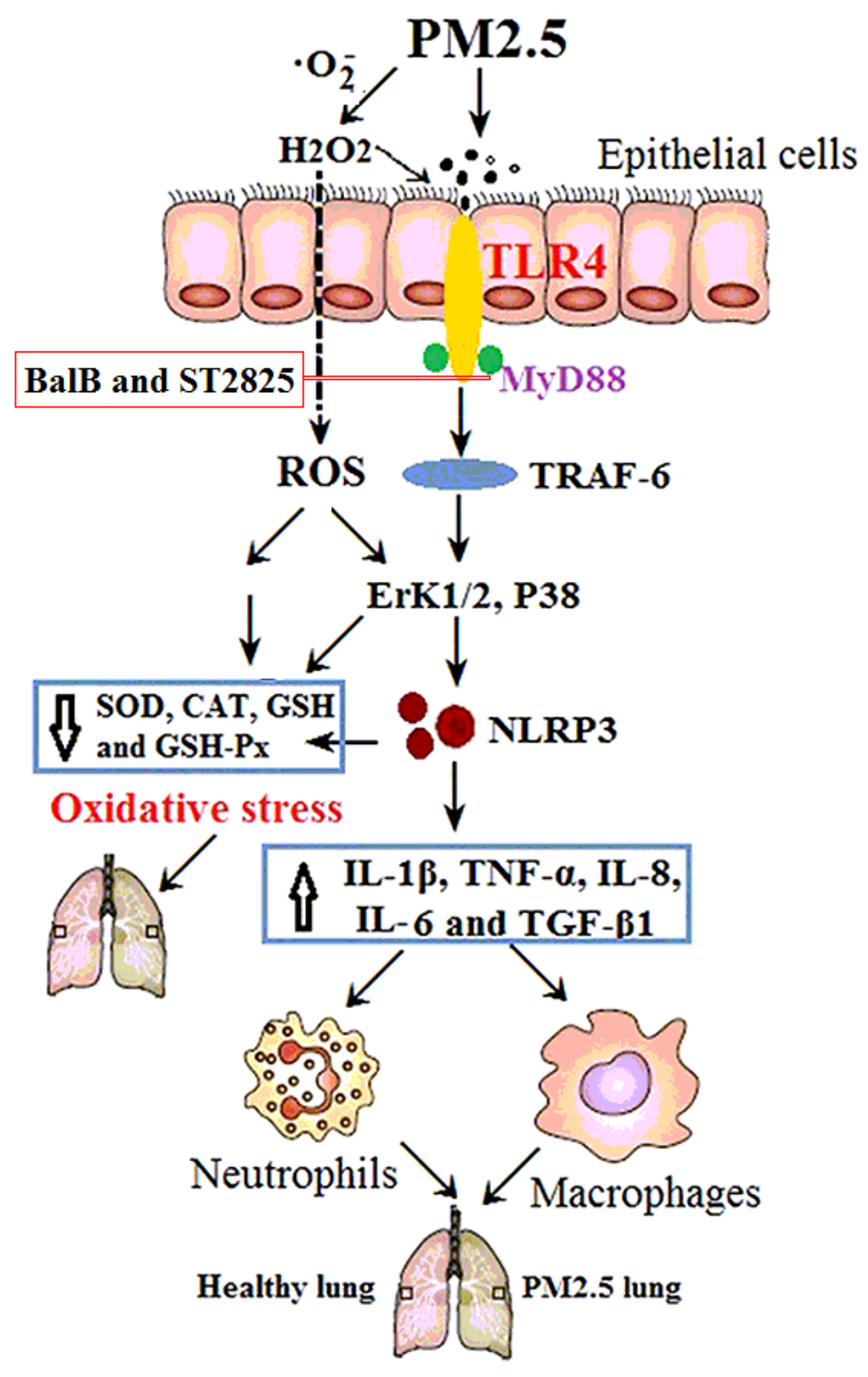

Figure 7

Scheme summarizing the protective effects of SalB inhalation on PM2.5-induced inflammatory and oxidation. SalB and ST2825 resulted in effective protection against PM2.5-induced acute airway inflammation and oxidative stress. These effects were closely correlated to the inhibition of the TLR4/MyD88/TRAF-6/ NLRP3 pathway and the activation of the ERK1/2 and P38 signaling pathway. 